\title{
Optimism for Africa
}

\author{
Materials research in Africa can contribute to addressing global challenges by tapping into a growing number of \\ talented scientists.
}

$\mathrm{H}$ istorically, there have been significant contributions from Africa in science and technology. Intriguingly, one of its major contributions has been in metallurgy. Ancient Egyptians experimented with a range of metals including copper and tin, eventually mixing them together to form alloys for tools and ornaments (pictured). They were so advanced in metal working that they developed techniques for exploration of mineral ores ${ }^{1}$. More recently, the African continent has provided a myriad of discoveries in health, some of which are still used in medicines today. Notable examples include pain remedies where Bantu tribes used the bark of the Salix capensis tree, which is now used in aspirin ${ }^{2}$. In addition, tetracycline in fermented brews was consumed by the Sudanese as an antibiotic ${ }^{3}$. Potent extracts are still being discovered in traditional remedies and are slowly being translated to modern medicines.

The success and ascendency of yesteryear has regrettably faded in recent times. This is largely driven by a number of factors such as unstable economies and political insecurity, which have hampered investment in research and development. In a recent report, the World Bank estimated that the allocation of funds for research in sub-Saharan Africa is less than $1 \%$ of the gross domestic product in the majority of countries ${ }^{4}$. This is reflected in the African scientific output, currently sitting at less than $5 \%$ of the total number of scientific publications, and largely driven by international collaborations. Reassuringly, however, this figure seems to have doubled over a decade from 2002 to 2013 in all areas of research, thanks to initiatives that aim to improve the scientific output. For example, in 2014, the World Bank set up the Partnership for Skills in Applied Science, Engineering and Technology (PASET) to help governments in sub-Saharan Africa accelerate investment in science and technology, and subsequently elevate a knowledge-based society (https://www.worldbank.org/paset). Moreover, increased support from governments in Africa to fund national institutions is also required to significantly impact research. A good example is the Botswana Institute for Technology Research and Innovation, which is contributing significantly to research and education in Botswana, particularly for materials science (https://www.bitri.co.bw/cms).
A major challenge is to develop sustainable means of harnessing available resources for long-term use. Research into minerals has made major contributions to the globe, particularly as modern societies become increasingly dependent on these resources for use in commodities such as electronics. However, mineral research is often driven by large international corporations rather than local institutions and local management. Educational institutions such as the Pan African University (PAU) were set up to foster fundamental and applied research in areas that are critical to the continent while also stimulating integration among African scientists $^{5}$. To date there have been five PAU institutes set up in locations around Africa, each specializing in thematic areas of water and energy, life and Earth sciences, space science and communication, basic sciences, and governance and humanities (https://pau-au.net/en/about-us). These institutions are funded by the host country, the African Union and thematic partners, and it is envisaged that they will grow to become major hubs in these areas of research.

Equally important is the need for a platform to showcase the findings of research activities taking place in Africa. To address this concern in materials science, the African Materials Research Society (AMRS) was set up to identify opportunities for collaboration between Africa, the US and the rest of the world to advance materials science research. Since its inaugural meeting in Dakar, Senegal, in 2002, the AMRS has grown substantially to a biennial event, with the recent meeting in Gaborone, Botswana, attended by over 500 delegates from 45 countries worldwide. Nature Materials has highlighted the AMRS previously ${ }^{6}$, and by Benjamin Hsiao and colleagues on page 213 of this issue. The conference showcased a diverse range of topics within materials science research centred on energy, water, health, nanotechnology, mining, computational materials science and education. Strikingly, an initiative that was borne out of the AMRS is the Joint US-Africa Materials Institute (JUAMI), which offers workshops for students from Africa and the US to identify global challenges and utilize materials research to address them ${ }^{7}$. These workshops have been successful at harnessing the potential of scientific talent. Other institutions and

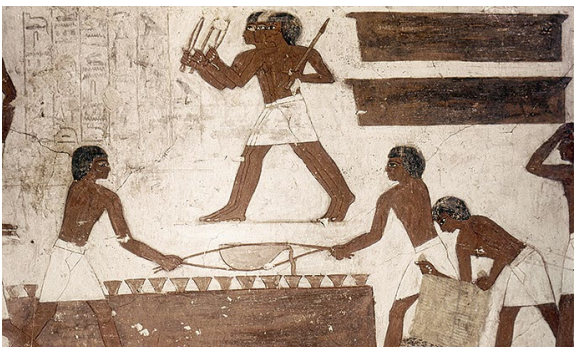

An Egyptian fresco from a tomb depicting foundry men casting bronze. Credit: Granger Historical Picture Archive/Alamy Stock Photo

initiatives have also been set up, some of which we have previously highlighted ${ }^{8}$. However, there is still a pressing need for developed countries such as the G7 to get further involved in sustaining such institutions ${ }^{9}$.

According to the recent World Economic Forum and the African Union Summit in 2018, it is clear that the challenges in Africa can be addressed by a shared responsibility and commitment to supporting existing enterprises in order to consolidate gains. Although there is a long road ahead to tackle major issues, multinational institutions such as PAU and platforms such as the AMRS and JUAMI are instrumental to the materials research community in Africa, which can have an impact on the rest of the world. Moreover, the eagerness of the youthful population and awareness of such initiatives will undoubtedly garner enthusiasm that will lead to research activities capable of tackling grand challenges, ultimately boosting African economies and wellbeing.

Published online: 21 February 2018 https://doi.org/10.1038/s41563-018-0037-1

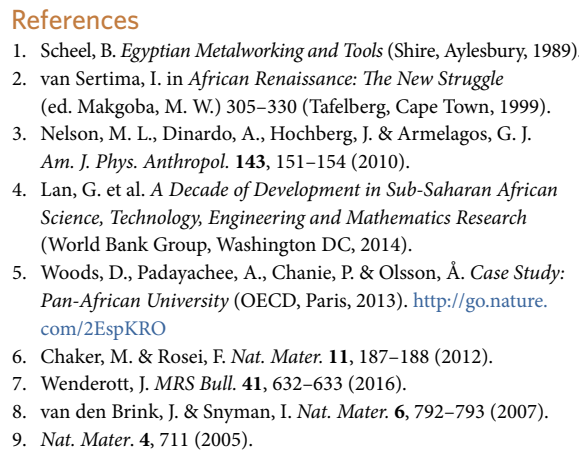

